\title{
Syncope caused by right ventricular obstruction by pectus excavatum
}

Suzanne Borrhomée, MD, ${ }^{\mathrm{a}}$ Marien Lenoir, MD, ${ }^{\mathrm{b}}$ Marielle Gouton, MD, ${ }^{\mathrm{a}}$ and Elie Fadel, MD, ${ }^{\mathrm{b}}$ Le Plessis Robison, France

From the Departments of ${ }^{\mathrm{a} C}$ Congenital Heart Disease and ${ }^{\mathrm{b}}$ Thoracic Surgery, Centre Chirurgical Marie Lannelongue, Le Plessis Robison, France.

Disclosures: Authors have nothing to disclose with regard to commercial support.

Received for publication Sept 6, 2015; accepted for publication Oct 8, 2015; available ahead of print Nov 4, 2015 Address for reprints: Suzanne Borrhomée, MD, Centre Chirurgical Marie Lannelongue, Intern, Congenital Heart

Disease, 111 Boulevard de la République, 95600 Eaubonne, France (E-mail: suzanne.borrhomee@ gmail.com). J Thorac Cardiovasc Surg 2016;151:e67-9

$0022-5223 / \$ 0.00$

Copyright $(2016$ by The American Association for Thoracic Surgery

http://dx.doi.org/10.1016/j.jtcvs.2015.10.018

Pectus excavatum (PE) is a chest wall deformity characterized by posterior intrusion of the chest wall into the thoracic cavity. It is usually a mild, asymptomatic condition, with an incidence ranging from 7 to 38 cases per 10,000 births, although this varies with ethnic origin. ${ }^{1}$ Coexistent $\mathrm{PE}$ and congenital heart disease (CHD) are rare $(0.17 \%)$, and combined correction of both abnormalities is controversial. ${ }^{2}$ Here we report a case of symptomatic PE in a patient with a history of repaired CHD.

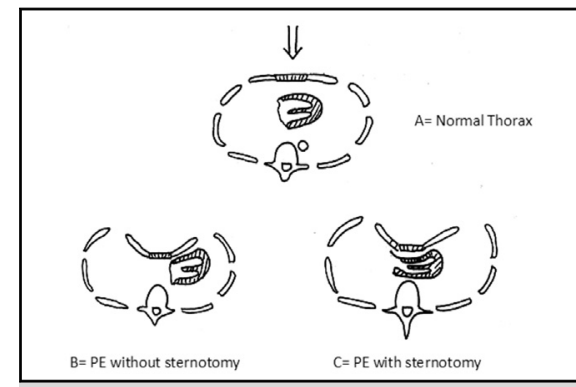

Diagram showing result of previous sternotomy on the heart in pectus excavatum.

\section{Central Message}

We report a case of pectus excavatum leading to syncope through major cardiac compression in a patient with previous cardiac surgery.

See Editorial Commentary page e69.

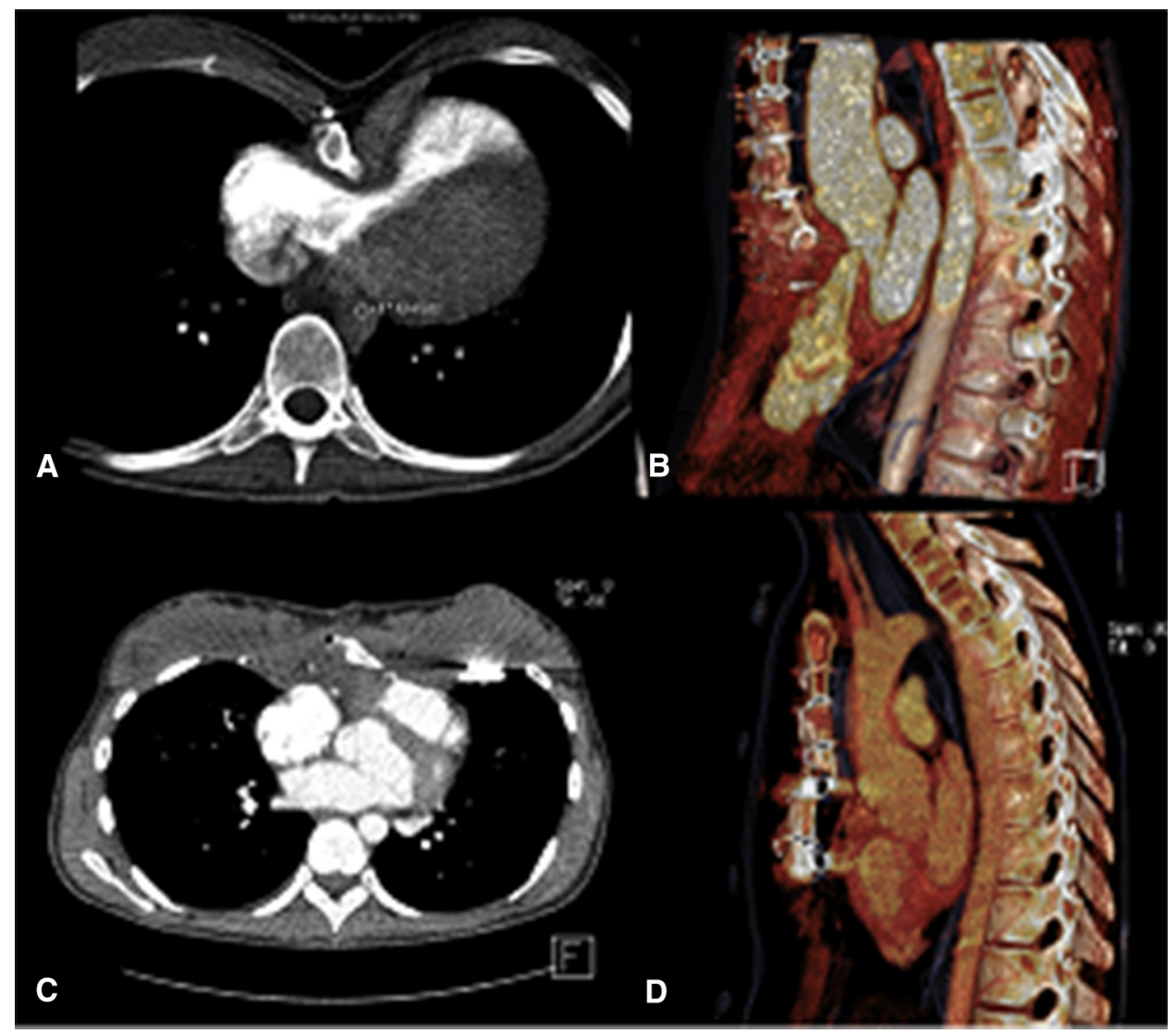

FIGURE 1. Computed tomographic scan of the chest wall. A and B, Preoperative view showing the chest wall deformity with the heart adherent to the sternum, causing severe compression of the right ventricle and right ventricular outflow tract, as well as associated with tricuspid valve stenosis from leaflet involvement. C and D, Postoperative computed tomographic scan showing the heart no longer compressed by the sternum. 


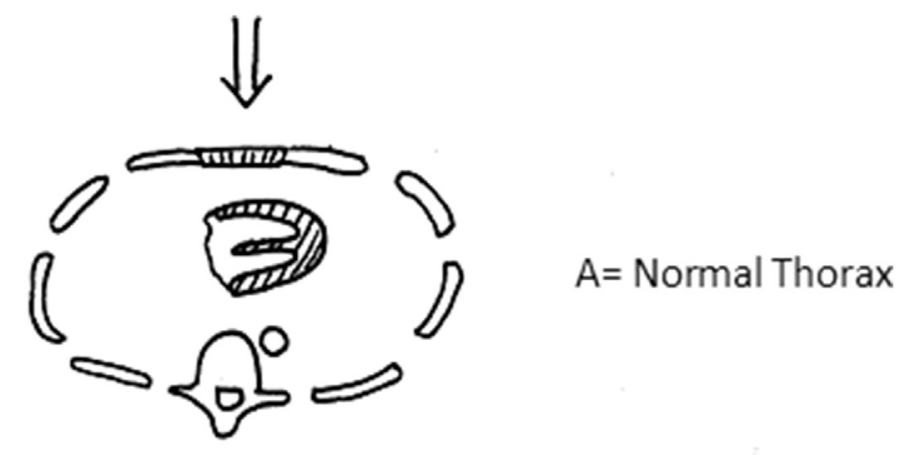

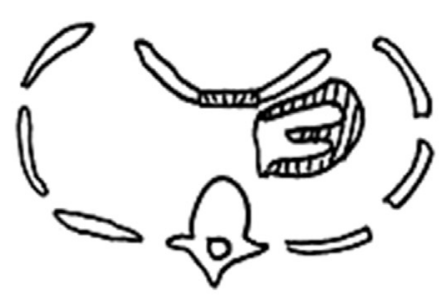

$\mathrm{B}=\mathrm{PE}$ without sternotomy

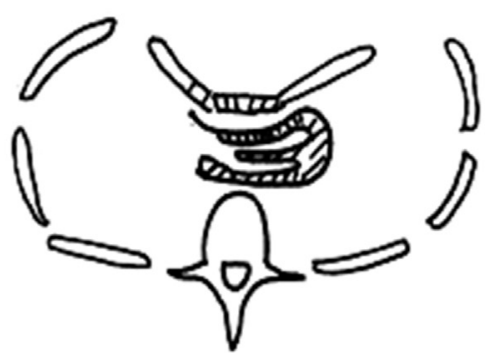

$\mathrm{C}=\mathrm{PE}$ with sternotomy

FIGURE 2. Diagram showing the hypothesized effects of previous sternotomy on the heart in pectus excavatum. A, Normal thorax. B, Pectus excavatum $(P E)$ without sternotomy, with the heart shifted to the left side of the chest without deformation. C, Pectus excavatum after sternotomy, with the heart compressed between the sternum and spine, resulting in right ventricular deformation.

\section{CLINICAL SUMMARY}

A 23-year-old woman was referred for recurrent syncope. At the age of 11 months, she had undergone repair of a ventricular septal defect and infundibular stenosis. The infundibular stenosis recurred, and she subsequently underwent a second operation at the age of 16 years. Both surgical procedures were performed through a median sternotomy. At the time of her second operation, she was noted to have a mild and asymptomatic PE with negligible cosmetic effects. Consequently, the PE was not repaired. After surgery, she was followed up regularly by medical examination and transthoracic echocardiography.

Three years after her second operation, the patient had a syncopal episode. She subsequently had multiple similar episodes, with the frequency rapidly increasing until she was having episodes on a weekly basis. Her syncope usually occurred during physical activity, and it began with dizziness or weakness that was immediately followed by a sudden loss of consciousness. Episodes typically resolved spontaneously after several seconds. Initial evaluation identified only premature atrial contractions, which did not explain her symptoms. She eventually underwent transthoracic echocardiography, which showed severe compression of the right ventricle (RV) by the sternum. This was also seen on computed tomographic scan (Figure 1).

Because of her severe symptoms, the decision was made to proceed with surgical correction. The patient subsequently underwent a Ravitch procedure, with resection of the sternal concavity, excision of subperichondrial cartilage, and fixation of the sternum and ribs with two titanium bars. Intraoperatively, dense adhesions between the sternum and the anterior mediastinum were observed and released. The postoperative course was uneventful, and the patient was discharged on postoperative day 5. Postoperative echocardiography showed major improvement in RV size and tricuspid valve function. At 6 months of follow-up, the patient reported no symptoms or syncopal episodes and had a satisfactory esthetic result.

\section{DISCUSSION}

Syncope is a rare presentation of PE, reported in only $8 \%$ of cases. ${ }^{3} \mathrm{PE}$ is usually asymptomatic, because as the patient grows and the PE becomes more pronounced, the heart gradually shifts toward the pleural cavity. This compensation prevents heart and lung compression in most cases. $\mathrm{PE}$ in the setting of CHD is also rare, occurring in $0.17 \%$ of cases, but the combination presents a unique challenge. After cardiac surgery, adhesions develop within the chest that can effectively fix the heart in position. This prevents the shifting required to compensate appropriately for the growing PE and can lead to cardiac compression (Figure 1).

Here we report a case of PE leading to major cardiac compression and disruption of RV filling. Because the patient had undergone multiple previous cardiac surgical 
procedures, this is likely a result of the described intrathoracic adhesions preventing normal compensation for progressively worsening PE. Compression of the RV likely lead to the patient's exercise-induced syncope, because physical exertion increases the heart rate and decreases filling time. In the setting of diastolic impairment from compression, this results in sudden diastolic heart failure and syncope (Figure 2). After surgical correction of the $\mathrm{PE}$, there was considerable relief of compression, with improvements in RV size and tricuspid valve function.

When PE occurs in the presence of CHD, surgical treatment should be considered at the time of the initial cardiac operation, even in the absence of standard indications. ${ }^{4}$ Such an approach has been reported with good technical results and overall outcomes. Many children with mild chest wall deformities, however, do not undergo surgical PE repair. ${ }^{2,4}$ Although CHD repair in early childhood does not prohibit future correction of $\mathrm{PE}$, postoperative adhesions that develop at an early age may prevent the compensatory shifting of the heart that occurs during growth and can result in dramatic cardiac compression. If the $\mathrm{PE}$ is not repaired at the time of the initial cardiac operation, the patient should be closely followed up with serial clinical examinations, transthoracic echocardiography, and, if needed, chest computed tomographic scans or other additional imaging modalities. Development of any cardiac compression must be identified early, because it significantly increases the risk of syncope, as seen in our patient, or even sudden cardiac death.

\section{References}

1. Chung CS, Myrianthopoulos NC. Factors affecting risks of congenital malformations. I. Analysis of epidemiologic factors in congenital malformations. Report from the Collaborative Perinatal Project. Birth Defects Orig Artic Ser. 1975;11:1-22.

2. Shamberger RC, Welch KJ, Castaneda AR, Keane JF, Fyler DC. Anterior chest wall deformities and congenital heart disease. J Thorac Cardiovasc Surg. 1988; 96:427-32.

3. Cobben JM, Oostra RJ, van Dijk FS. Pectus excavatum and carinatum. Eur J Med Genet. 2014:57:414-7.

4. Kelly RE Jr. Pectus excavatum: historical background, clinical picture, preoperative evaluation and criteria for operation. Semin Pediatr Surg. 2008;17: 181-93.

5. Mocchegiani R, Badano L, Lestuzzi C, Nicolosi GL, Zanuttini D. Relation of right ventricular morphology and function in pectus excavatum to the severity of the chest wall deformity. Am J Cardiol. 1995;76:941-6.

\section{EDITORIAL COMMENTARY}

\section{What are the indications for pectus excavatum repair at the time of congenital cardiac surgery: Separating theory from reality}

\author{
Alexander Sasha Krupnick, MD \\ From the Division of Cardiothoracic Surgery, Department of Surgery, Washington University in St Louis, \\ St Louis, Mo. \\ Disclosures: Author has nothing to disclose with regard to commercial support. \\ Received for publication Dec 8, 2015; accepted for publication Dec 10, 2015; available ahead of print Jan 15, \\ 2016. \\ Address for reprints: Alexander Sasha Krupnick, MD, Division of Cardiothoracic Surgery, Department of \\ Surgery, Washington University in St Louis, Campus Box 8234, 660 South Euclid Ave, St Louis, MO 63110 \\ (E-mail: krupnicka@wudosis.wustl.edu). \\ J Thorac Cardiovasc Surg 2016;151:e69-70 \\ $0022-5223 / \$ 0.00$ \\ Published by Elsevier Inc. on behalf of The American Association for Thoracic Surgery \\ http://dx.doi.org/10.1016/j.jtcvs.2015.12.016
}

Pectus excavatum (PE) in some form affects $0.1 \%$ of the population, with $10 \%$ to $20 \%$ of patients eventually seeking surgical consultation for repair. ${ }^{1}$ On the basis of national practice patterns, most patients seek the consultation of a general pediatric surgeon for repair during childhood or adolescence. Thus, congenital chest wall deformities represent only a small fraction of the average thoracic surgeon's practice, leading to limited experience

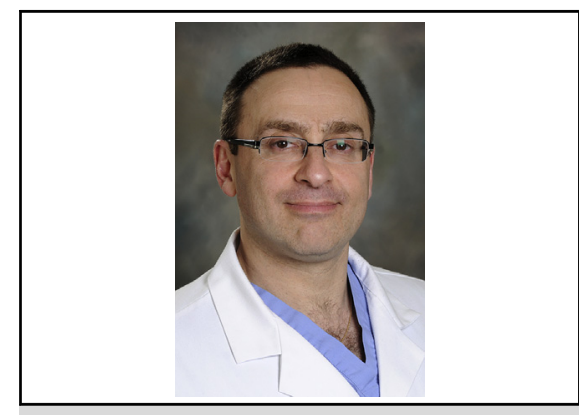

Alexander Sasha Krupnick, MD

Central Message

The combination of PE and congenital cardiac defects requiring surgical repair presents a difficult therapeutic dilemma.

See Article page e67. 